\title{
Pembangkitan Terahertz pada Metamaterial Chiral Menggunakan Spektroskopi Emisi Terahertz
}

\author{
Juliasih Partini ${ }^{*}$, dan Restu Widiatmono ${ }^{2}$ \\ ${ }^{1}$ Departemen Fisika FMIPA UGM, Yogyakarta \\ ${ }^{2}$ Jurusan Pendidikan Fisika, FMIPA UNY, Yogyakarta \\ juliasih@ugm.ac.id
}

\section{ABSTRACT}

Metamaterial is an artificial material which has a negative refractive index. Both of permitivitty and permeability have a negative value to possess negative refraction. The breakthrough of metamaterial development was present as the invention of chiral structure metamaterial, espescially as a terahertz (THz) source. THz emission was measured using a femtosecond Ti:Sapphire pumped terahertz emission spectroscopy system. The chiral metamaterial samples have physical size as follows: length $1,2 \mu \mathrm{m}$, width $0,3 \mu \mathrm{m}$, and depth $0,3 \mu \mathrm{m}$. It has been produced dua chiral metamaterial samples, which are 300 periodic square pattern samples which consist of a clock-wise as a right-hand sample and a counter clock-wise as a left-hand sample. The all of samples were capable to generate a THz emission over a frequency range of $0-2,24 \mathrm{THz}$. THz signal was occurred due to the optical rectification process as a result of an intense femtosecond laser pulses radiation on a chiral metamaterial sample. The experiment result showed that the relation between the pumping laser energy and the generated THz amplitude was a second-order function. It can be concluded that chiral metamaterial with different depth has been successfully generate elliptic polarized $\mathrm{THz}$ emission.

Keywords : Terahertz, chiral metamaterials, terahertz emission

ABSTRAK

Metamaterial adalah material buatan dengan indeks bias negatif dan secara simultan memiliki permitivitas elektrik dan permeabilitas magnetik bernilai negatif. Pengembangan metamaterial mengalami terobosan dengan munculnya struktur metamaterial baru yang disebut sebagai metamaterial struktur chiral sebagai sumber radiasi terahertz $(\mathrm{THz})$. Pengukuran sinyal emisi $\mathrm{THz}$ dilakukan menggunakan sistem spektroskopi emisi terahertz dengan sistem laser Ti:Sapphire femtosekon sebagai sumber radiasi. Sampel metamaterial chiral dengan ukuran panjang $1,2 \mu \mathrm{m}$, lebar $0,3 \mu \mathrm{m}$ dan kedalaman 0,3 $\mu \mathrm{m}$ susunan 300 struktur dengan arah putar kanan dan putar kiri. Kedua sampel mampu membangkitkan emisi gelombang THz dalam jangkau frekuensi $0-2,24 \mathrm{THz}$. Proses rektifikasi optik diperlihatkan oleh adanya pembangkitan gelombang $\mathrm{THz}$ pada sampel metamaterial chiral oleh laser femtosekon. Hasil eksperimen memperoleh hubungan kuadratik antara energi laser pemompa dengan amplitudo gelombang THz. Hal ini dapat disimpulkan bahwa metamaterial chiral persegi dengan kedalaman berbeda telah berhasil membangkitkan emisi gelombang THz yang terpolarisasi eliptik.

Kata kunci : Terahertz, metamaterial chiral, emisi terahertz 


\section{PENDAHULUAN}

Ranah frekuensi terahertz (THz) baik mengenai sumber radiasi, detektor, antena, spektroskopi, pencitraan dan lain-lain, merupakan salah satu topik riset yang cukup banyak menarik perhatian pada saat ini. Frekuensi sumber radiasi ini berada di antara $300 \mathrm{GHz}$ sampai $3 \mathrm{THz}$ atau pada panjang gelombang 0,1 mm sampai $1 \mathrm{~mm}$. Sumber-sumber yang tersedia saat ini baik dari kelompok elektronik maupun dari fotonik masih memiliki keluaran pada level microwatt ${ }^{[1]}$. Hal ini memunculkan agresivitas penelitian karena letak frekuensi $\mathrm{THz}$ ini berada belum banyak dijangkau oleh sumber gelombang lain yang dibuat oleh manusia. Frekuensi THz memberi kemungkinan untuk mendeteksi material yang tersimpan di dalam suatu obyek. Gelombang THz dapat menembus berbagai material seperti tembok, pakaian, pembungkus paket, dan lainnya dari jarak ratusan meter, tetapi tidak akan menembus jaringan tubuh manusia. Radiasi $\mathrm{THz}$ dengan demikian mampu menjadi sumber yang ideal untuk mendeteksi benda-benda yang tersembunyi di balik baju. ${ }^{[2]}$ Gelombang $\mathrm{THz}$ juga dapat digunakan untuk mendeteksi komposisi kimia sebuah material ${ }^{[3]}$. Pada bidang komunikasi, ranah frekuensi THz menjanjikan super-broadband atau transfer data yang berlipat-lipat dari capaian yang ada pada saat ini ${ }^{[4]}$. Penelitian terkini menunjukkan ranah frekuensi ini mulai banyak digunakan untuk deteksi, sensor, maupun pencitraan biomedis ${ }^{[5]}$. Perkembangan terbaru penggunaan sumber gelombang $\mathrm{THz}$ telah membuka kesempatan untuk memunculkan efek non linier pada material-material baru, seperti semikonduktor ${ }^{[6]}$, sumur kuantum ${ }^{[7]}$, ferroelectric ${ }^{[8]}$ maupun metamaterial konvensional [9].

Rektifikasi optik merupakan salah satu proses yang terjadi dalam optika non linier orde dua yang dijelaskan dari sifat simetri medium non linier yang menghasilkan polarisasi dc pada gelombang sinusoidal ${ }^{[10]}$. Rektifikasi optik mampu mengubah medan listrik sinusoidal menjadi polarisasi searah. Perubahan polarisasi ini terjadi jika terjadi cahaya datang dengan intensitas yang meningkat ${ }^{[11]}$. Gambar 1 menunjukkan mekanisme pembangkitan gelombang THz pada proses rektifikasi optik. Cahaya dengan intensitas tinggi, dalam hal ini laser pulsa femtosekon, ditembakkan pada suatu bahan non linier. Interaksi laser pulsa dengan medium akan menghasilkan polarisasi non linier pada bahan.

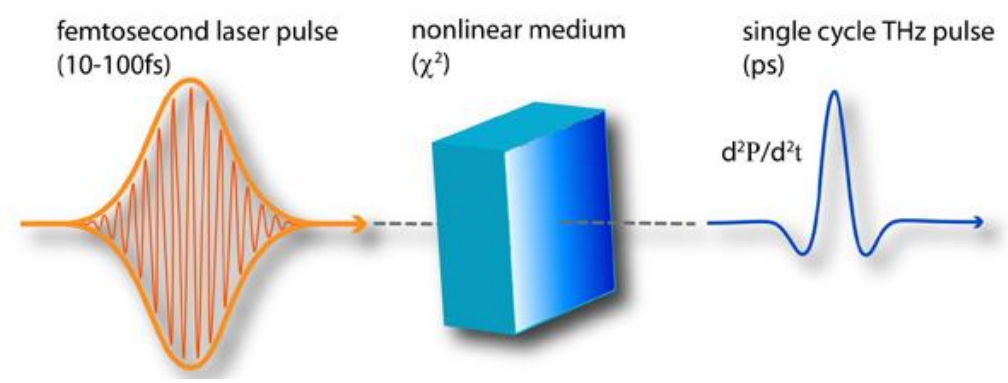

Gambar 1. Mekanisme pembangkitan gelombang $\mathrm{THz}$

Pada proses rektifikasi optik, berlangsung proses percepatan/perlambatan muatan (yang terikat dalam bentuk dipol) serta pembangkitan gelombang $\mathrm{THz}$ yang bergantung pada suseptibilitas orde dua $(\chi)$ dari bahan non linier optik yang digunakan. Bahan yang umum digunakan pada detektor pembangkitan radiasi jangkau $0,5-3 \mathrm{THz}$ adalah $\mathrm{ZnTe}$ (Zinc telluride). Seperti halnya pada proses optika non linier yang lain, maka pada rektifikasi optik juga didapatkan penguatan (enhanced) saat surface plasmon tereksitasi pada permukaan metal yang digunakan. Pada rektifikasi optik juga berlangsung proses pengepasan fase 
optika di bahan nonsentrosimetrik seperti $\mathrm{ZnTe}$ dan $\mathrm{LiNbO}_{3}{ }^{[12]}$. Koefisien konversi dari energi gelombang cahaya tampak menjadi energi gelombang $\mathrm{THz}$ masih sangat terbatas nilainya yaitu $10^{-6}$ sampai $10^{-9}$. Selain itu, penelitian rektifikasi optik yang merupakan salah satu tanggap non linier pada suatu material menjadi sangat menantang, karena masih minimnya sumber bahan non linier yang dapat digunakan dalam ranah $\mathrm{THz}^{[13]}$.

Riset metamaterial telah diawali dengan kajian teoritis sifat-sifat elektrodinamika bahan berindeks bias negatif dan visualisasi grafisnya. Riset teoritis ini kemudian dilanjutkan dengan kajian yang lebih spesifik tentang magnetic surface plasmon resonance pada bahan metamaterial. Secara khusus riset metamaterial chiral diawali pengusul dengan melakukan kajian teoritis gejala non linear pada bahan metamaterial dan gejala circular dichroism pada metamaterial chiral ${ }^{[14]}$. Hasil yang diperoleh memperlihatkan adanya perubahan polaritas dan eliptisitas pada struktur chiral yang digunakan. Berdasarkan hasil tersebut, dilakukan penelitian yang difokuskan pada struktur chiral yang dibuat di atas suatu lapisan tipis perak menggunakan sistem Focused Ion Beam (FIB). Spektroskopi Emisi Terahertz digunakan untuk menyelidiki munculnya pancaran sinyal $\mathrm{THz}$ yang merupakan gejala optika non linier pada struktur metamaterial chiral. Hal ini dilakukan untuk melihat performa bahan metamaterial yang dikembangkan sebagai alternatif sumber radiasi terahertz ${ }^{[15]}$.

\section{METODE}

Bahan utama yang digunakan dalam penelitian adalah metamaterial chiral struktur persegi berbahan dasar perak (Ag) dengan dua arah putaran yang berbeda. Gambar 2 memperlihatkan pola desain chiral dengan ukuran struktur chiral persegi dengan panjang $1,2 \mu \mathrm{m}$, lebar $0,3 \mu \mathrm{m}$, dan kedalaman $0,3 \mu \mathrm{m}$. Arah panah yang membentuk arah putar kanan atau putar kiri menunjukkan kedalaman yang berbeda pada tiap pola persegi yang dibentuk di atas lapisan tipis perak.

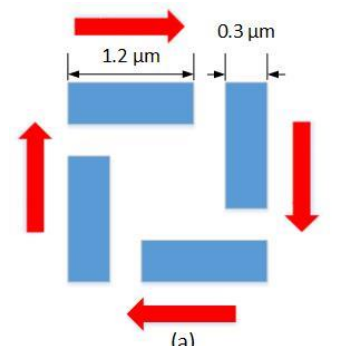

(a)

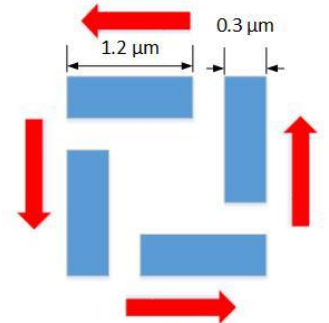

(b)

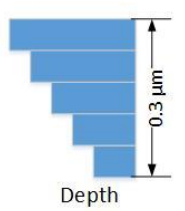

(c)

Gambar 2. Desain Metamaterial Chiral (a) sampel 1 (arah ) (b) sampel 2 (arah putar kiri) (c) kedalaman pola sampel

Fabrikasi sampel menggunakan Focus Ion Beam (FIB) menghasilkan sampel yang mewakili perbedaan putaran chiral dan perbedaan jumlah struktur, yakni sampel 1 yang merupakan metamaterial chiral persegi yang terdiri dari 300 struktur putar kanan (searah jarum jam) dan Sampel 2 berupa metamaterial chiral persegi yang terdiri dari 300 struktur putar kiri (berlawanan arah jarum jam). Gambar 3 memperlihatkan beberapa citra SEM yang diperoleh, yakni (a) Sampel 1 (LEI) dengan perbesaran 17.000 (b) Sampel 1 (LEI) dengan perbesaran 9.000 (c) Sampel 2 (SEI) dengan perbesaran 12.000 dan (d) Sampel 2 (SEI) dengan perbesaran 5.000 . 


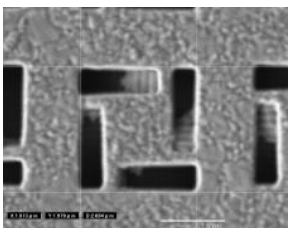

(a)

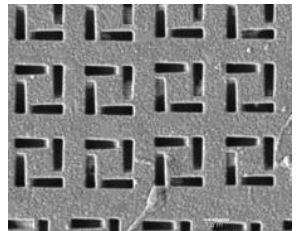

(b)

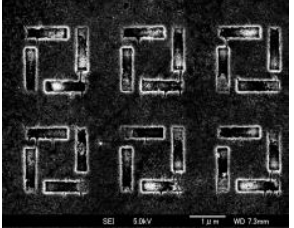

(c)

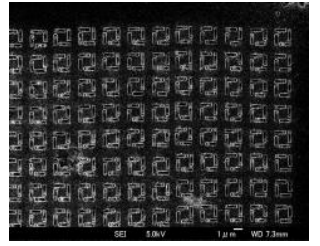

(d)

Gambar 3. Pengamatan SEM metamaterial chiral

Citra SEM metamaterial pada Gambar 3 menunjukkkan gradasi warna hitam pada setiap persegi yang ada di struktur chiral, baik untuk sampel dengan putar kiri maupun putar kanan. Gradasi warna hitam menunjukkan kedalaman sampel yang berbeda, yang menjadi dasar adanya chirality pada struktur chiral. Hasil pengamatan SEM secara keseluruhan memperlihatkan bahwa metamaterial chiral persegi yang dihasilkan memiliki permukaan planar dan tidak memiliki cacat pada struktur maupun permukaan material. Pengukuran tanggap non linear pada sampel metamaterial chiral persegi menggunakan spektroskopi emisi terahertz. Gambar 4 menunjukkan susunan sistem spektroskopi emisi terahertz yang digunakan dalam eksperimen ini.

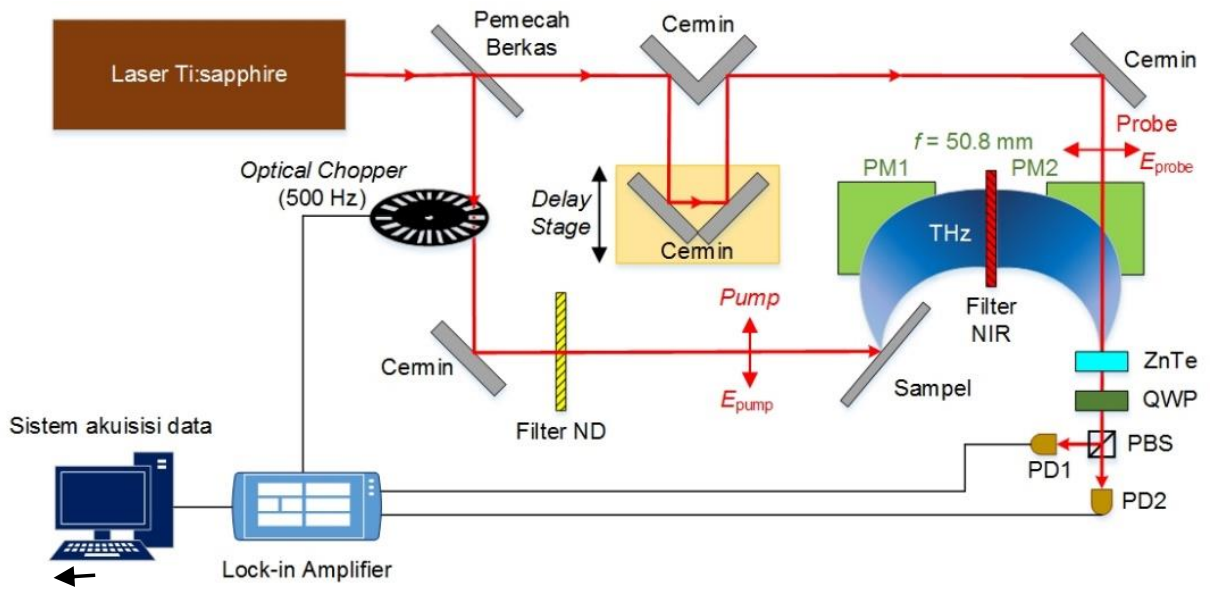

Gambar 4. Skema Spektroskopi Emisi Terahertz

Sistem spektroskopi ini menggunakan sumber radiasi berupa laser Ti:Sapphire amplified regeneratif $100 \mathrm{fs}$ dengan panjang gelombang sentral $800 \mathrm{~nm}$. Laser ini, dalam pengukuran sinyal Terahertz, menggunakan mode signal pulsa. Berkas laser Ti:Sapphire kemudian terbagi menjadi dua, yakni berkas laser probe dan berkas laser pemompa, dengan menggunakan sebuah Beam Splitter (BS). Berkas laser pemompa melewati chopper yang diatur pada frekuensi $500 \mathrm{~Hz}$ dan kemudian mengenai sampel metamaterial chiral yang ditempatkan pada posisi $45^{\circ}$ terhadap arah datangnya berkas. Serapan energi laser oleh sampel metamaterial chiral akan menyebabkan proses non-linear di dalam matamaterial dan menghasilkan emisi THz. Setelah sampel mampu menghasilkan emisi THz, digunakan NIR filter (berupa gabus polystyrene yang dilengkapi dengan polyethylene hitam) untuk mengantisipasi kemungkinan kebocoran berkas NIR yang menyertai gelombang THz. Emisi $\mathrm{THz}$ yang diperoleh kemudian digabungkan dengan berkas laser probe yang menuju ke detektor elektro optik ZnTe. Parabolic mirror (PM) digunakan untuk mengarahkan emisi $\mathrm{THz}$ tersebut agar emisi yang dihasilkan bertemu dengan berkas laser probe dan menuju ke detektor. Sinyal keluaran dari fotodetektor kemudian dimasukkan ke sebuah lock-in amplifier. Berkas laser probe pada saat bersamaan diarahkan melalui sebuah delay stage yang diatur menggunakan program Labview 210. Perangkat yang digunakan dalam 
pengaturan ini adalah Labview 210, SR830 lock-in amplifier dan Mark-204 Storage Controller.

Sinyal $\mathrm{THz}$ diperoleh melalui scanning delay stage berkas probe serta mencatat respon fotodioda pada tiap-tiap waktu. Transformasi fourier digunakan untuk mendapatkan spektrum sinyal $\mathrm{THz}$ dalam fungsi frekuensi. Analisa hasil sinyal $\mathrm{THz}$ digunakan untuk memahami mekanisme pembangkitan gelombang $\mathrm{THz}$ sebagai salah satu hasil proses interaksi non linier antara gelombang elektromagnetik dengan medium chiral. Analisa rektifikasi optik didasarkan pada pengukuran amplitudo sinyal $\mathrm{THz}$ terhadap input daya laser femtosekon yang digunakan.

\section{HASIL DAN PEMBAHASAN}

Analisis gejala optika non linear pada metamaterial chiral dilakukan dengan spektrum emisi yang terbentuk pada masing-masing sampel. Hasil ini digunakan untuk menguji kemampuan sampel untuk memancarkan gelombang $\mathrm{THz}$. Waveform $\mathrm{THz}$ diperoleh berdasarkan scanning pada delay stage berkas probe serta respon fotodioda untuk tiap satuan waktu tunda. Spektrum emisi THz pada metamaterial chiral persegi yang tersusun atas 300 struktur memiliki bentuk sinyal seperti yang nampak pada Gambar 5 dan Gambar 6.

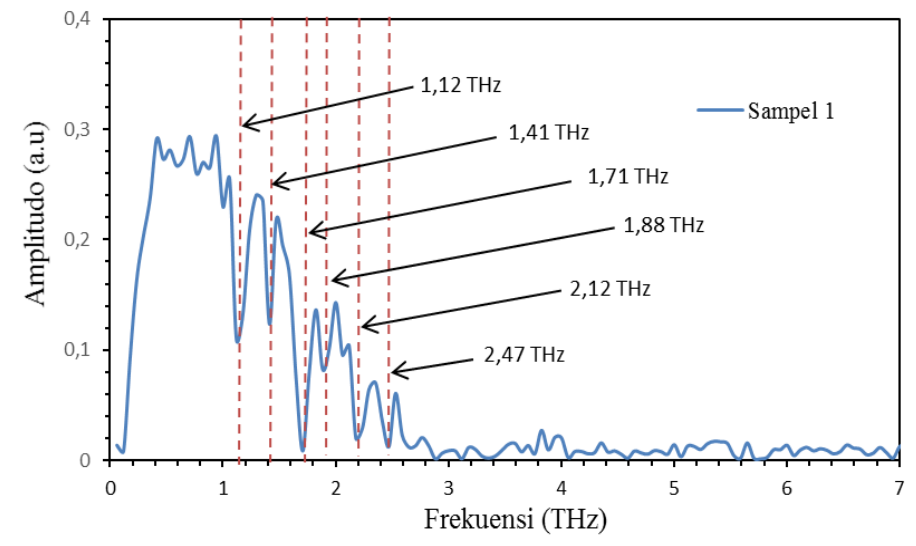

Gambar 5. Spektrum THz metamaterial chiral struktur putar kanan (Sampel 1)

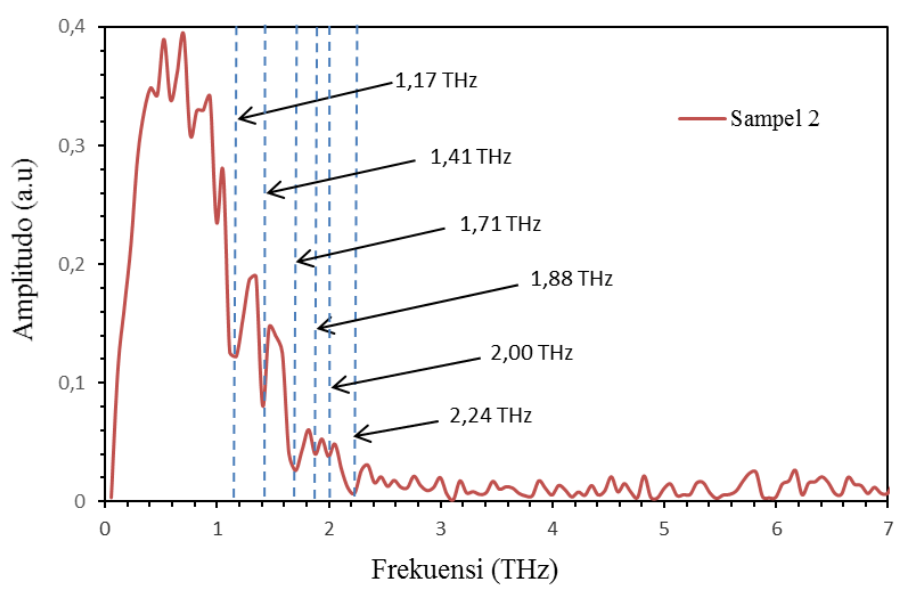

Gambar 6. Spektrum THz metamaterial chiral struktur putar kiri (Sampel 2)

Sampel 1 dan sampel 2 dalam masing-masing gambar adalah sampel metamaterial chiral yang memiliki susunan 300 struktur dengan arah putaran yang berbeda. Sinyal yang terukur merupakan amplitudo medan listrik gelombang $\mathrm{THz}$ yang sebanding dengan intensitas 
gelombang THznya. Spektrum THz untuk sampel metamaterial chiral, baik untuk arah putar kanan maupun putar kiri, menunjukkan bahwa emisi THz berlangsung dalam frekuensi 0 2,24 THz. Amplitudo pada spektrum $\mathrm{THz}$ metamaterial chiral persegi putar kiri nampak sedikit lebih tinggi dibanding dengan amplitudo pada sampel metamaterial chiral persegi putar kanan. Hal ini menunjukkan adanya peningkatan surface plasmon pada permukaaan sampel metamaterial chiral persegi putar kiri yang bersesuaian dengan frekuensi emisi gelombang THz. Garis-garis serapan dengan besar frekuensi yang hampir sama pada spektrum THz di kedua sampel menunjukkan gejala yang sama menyertai proses emisi THz. Garis-garis serapan ini muncul karena adanya serapan molekul uap air pada frekuensi $\mathrm{THz}$ di sekitar sampel. Hal ini menegaskan bahwa ketidakhalusan spektrum emisi $\mathrm{THz}$ yang dihasilkan oleh sampel metamaterial chiral memang disebabkan oleh serapan uap air di sekitar sampel. Beberapa penelitian yang mengimplementasikan box vakum udara pada setup spektroskopi terahaertz mampu mengurangi pengaruh serapan uap air di sekitar sampel. Spektrum kontinyu yang diperoleh menjadi lebih halus tanpa kehadiran garis-garis serapan dalam jangkau frekuensi emisi tersebut ${ }^{[16]}$.

Proses rektifikasi optik pada sampel metamaterial dapat diamati dengan melakukan variasi energi laser pemompa dan melihat pengaruhnya terhadap sinyal emisi THz yang dihasilkan. Hasil pengukuran variasi daya laser pemompa (pump power) terhadap amplitudo gelombang THz pada sampel metamaterial chiral ditunjukkan pada Gambar 6. Pada gambar tersebut, keterangan angka dalam tanda kurung menunjukkan hubungan pangkat antara gelombang $\mathrm{THz}$ dengan laser pemompa yang digunakan.

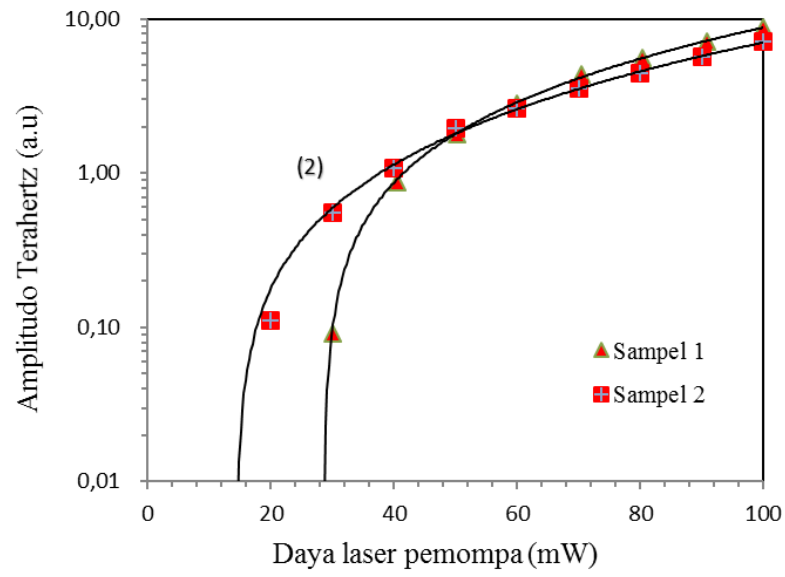

Gambar 6. Grafik logaritmik rektifikasi optik sampel metamaterial chiral

Hasil fitting data kedua grafik logaritmik rektifikasi optik menyatakan bahwa sinyal emisi $\mathrm{THz}$ yang diperoleh sebanding dengan pangkat dua energi laser yang digunakan. Karakteristik optika non linier suatu material dijabarkan dengan menguraikan polarisasi non linier $P_{\mathrm{NL}}$ dalam fungsi pangkat medan listrik $E$ Dapat disimpulkan bahwa polarisasi non linier tersebut sebanding dengan pangkat dua dari medan listriknya. Polarisasi non linier mewakili gelombang $\mathrm{THz}$ sedangkan medan listrik mewakili energi laser pemompa, sehingga dapat dinyatakan bahwa gelombang $\mathrm{THz}$ yang muncul pada proses rektifikasi optik sebanding dengan pangkat dua laser pemompanya.

\section{KESIMPULAN}

Kedua sampel mampu membangkitkan emisi gelombang THz dalam jangkau frekuensi 0 2,24 THz. Respon non linear pada sampel metamaterial ditinjau dari proses rektifikasi optik. 
Proses ini juga diperlihatkan oleh adanya pembangkitan gelombang THz pada sampel metamaterial chiral oleh laser femtosekon. Pada gelombang THz, energi laser pemompa akan sebanding dengan medan listrik dan amplitudo sebanding dengan polarisasi non liniernya. Hasil penelitian menunjukkan hubungan kuadratik antara energi laser pemompa dengan amplitudo gelombang THz.

\section{DAFTAR PUSTAKA}

1 Peter, H., \& Siegel, P.H. 2002. Terahertz technology. IEEET Microwave Theory, 50, 910 $-928$

2 Parthasarathy, R., Globus, T., Khromova, T., Swami, N., \& Woolard, D. 2005. Dielectric properties of biological molecules in the Terahertz gap. Applied Physics Letters, 87, 11, 113901

3 Davies, A. G., Burnett, A. D., Fan, W., Linfield, E H., \& Cunningham, J. E. 2008. Terahertz spectroscopy of explosives and drugs. Materials Today, 11, 3, $18-26$

4 Dragoman, D. 2004. Terahertz Fields and Applications. Progress in Quantum Electronics, 28, 1, $1-66$

5 Sigh, R., Plum, E., Zhang, W., \& Zheludev, N. 2010. Highly tunable optical activity in planar achiral terahertz metamaterials. Optics Express, Vol. 18, No. 13, 13425 - 13430

6 Fan, K., Hwang, H.Y., Liu M., Strikwerda, A.C., Sternbach, A., Zhang, J., Zhao, X., Zhang, X., Nelson, K.A., \& Averitt, R.D. 2013. Nonlinear terahertz metamaterials via field-enhanced carrier dynamics in GaAs. Physical Review Letters, 110, 217404

7 Hirori, H., Nagai, M., \& Tanaka, K. 2010. Excitonic interactions with intense terahertz pulses in ZnSe/ZnMgSSe multiple quantum wells. Physical Review B, 81, 081305

8 Katayama, I., Aoki, H., Takeda, J., Shimosato, H., Ashida, M., Kinjo, R., Kawayama, I., Tonouchi, M., Nagai, M., \& Tanaka, K. 2012. Ferroelectric soft mode in a SrTiO3 thin film impulsively driven to the anharmonic regime using intense picosecond terahertz pulses. Physical Review Letters, 108, 097401

9 Wang, B., Zhou, J., Koschny, T., \& Soukoulis, C.M. 2009. Nonplanar Chiral Metamaterials with Negative Index. Applied Physics Letters, 94, 151112

10 Kadlec, F., Kuzel, P., \& Countaz, J.L. 2005. Study of terahertz radiation generated by optical rectification on thin gold films. Optics Letters, Vol. 30, No. 11, $1402-1404$

11 Hatano, T., Nishikawa, B., Iwanaga, M, \& Ishihara, T. 2008. Optical rectification effect in 1D metallic photonic crystal slabs with asymmetric unit cell. Optics Express, Vol. 16, No. 11, $8236-8241$

12 Kanda, N., Konishi, \& Kuwata-Gonokami, M. 2007. Terahertz wave polarization rotation with double layered metal grating of complimentary chiral patterns. Optics Express, Vol. 15, No 18, 11117 - 111125

13 Liu, H., Li, G.X., Li, K.F., Chen, S.M., Zhu, S.N, Chan, C.T., \& Cheah, K.W. 2011. Linear and nonlinear Fanoresonance on two-dimensional magnetic metamaterials. Physical Review B, 84, 235437

14 Juliasih, P., Kamsul, A., \& Arief, H. 2017. Chirality Analysis on a Square Chiral Metamaterial. Materials Science Forum, Vol 901, 65-68

15 Juliasih, P., Kamsul, A., Arief, H., Satoshi, T., \& Matsui, T. 2015. Terahertz Signal Measurement on a Chiral Metamaterial Using Terahertz Emission Spectroscopy. Applied Mechanics and Materials. Vol. 771, 125 - 128

16 Ramakrishnan, G., \& Planken, C.M. 2011. Percolation-enhanced generation of terahertz pulses by optical rectification on ultrathin gold film. Optics Letters, Vol. 36, No. 13, $2572-2574$ 